\title{
Urban Agriculture and Urban Food Insecurity in Maseru, Lesotho
}

\author{
Jonathan Crush $^{1}$, Bruce Frayne ${ }^{2}$, Cameron McCordic ${ }^{1, *}$ \\ ${ }^{1}$ Balsillie School of International Affairs, Wilfrid Laurier University, Waterloo, Canada \\ ${ }^{2}$ School of Environment, Enterprise and Development, University of Waterloo, Waterloo, Canada \\ *Corresponding author: cmccordic@balsillieschool.ca
}

\begin{abstract}
Lesotho is facing continued and widespread food insecurity. In spite of a rapidly growing urban population, food security interventions and paradigms have primarily focused on bolstering food production within the country. This paper assesses the extent to which household engagement in urban agriculture in Maseru is associated with improved food security. Using household survey data, the paper argues that there is no consistent and statistically-significant relationship between urban agriculture practice and food security among Maseru households. Furthermore, some urban agriculture practices were only associated with significantly greater odds of food security for middle-income households in the sample. Given the that the observed benefits of urban agriculture appear to be conditional upon household income, this study suggests that a generalized production-centred approach to food insecurity may not be the most effective means of addressing household food security in Maseru.
\end{abstract}

Keywords: urban agriculture, urban food security, poverty, Maseru, Lesotho

Cite This Article: Jonathan Crush, Bruce Frayne, and Cameron McCordic, "Urban Agriculture and Urban Food Insecurity in Maseru, Lesotho.” Journal of Food Security, vol. 5, no. 2 (2017): 33-42. doi: 10.12691/jfs-5-2-3.

\section{Introduction}

Urban agriculture (UA) is widely viewed as a panacea for the growing challenge of urban food insecurity in African cities [1,2,3,4,5]. The idea that poor urban populations should and could grow their own food achieved significant credibility in the 1990s and has begun to resurface in recent policy debates. While much of the literature is extremely enthusiastic about the practice and promise of urban agriculture, more critical perspectives are also emerging $[5,6,7,8]$. One line of criticism is that urban agriculture advocates assume that the fundamental problem and solution for urban food security lies in the realm of food production and availability, ignoring other well-documented dimensions of food security including food access, food stability and food utilization.

Most of the policy enthusiasm for urban agriculture in the 1990s passed Lesotho by. Although the Bureau of Statistics has assiduously collected national data on the extent and types of urban agriculture for a number of years, there has not been systematic policy uptake to date $[9,10]$. None of the country's major development and food security strategies explicitly identified urban food insecurity and urban agriculture as a programming focus, for example $[11,12,13,14]$. The reason for Lesotho's omission from UA discourse is rooted in the tired misconception that it is a rural country and the vast majority of the population relies on subsistence agriculture [15]. As a result, the challenge of food insecurity is generally seen as a rural agricultural problem requiring increased smallholder production and productivity. This, of course, is also consistent with the productionist policy prescriptions of the international and African food security agenda [16].

The location of Lesotho's food security strategy and action plan in the Ministry of Agriculture and Food Security reinforces the idea that food security is primarily a rural agricultural challenge. In fact, rural development interventions designed to rehabilitate smallholder farming in Lesotho have a long and checkered history dating back well into the colonial period [17]. Despite the continuing injection of large sums of foreign aid directed at rural development in the post-colonial period, agricultural production continues its inexorable decline. Domestic food production now meets less than a third of the food requirements of the country, the area being cultivated is in decline, and agricultural output is falling. As the cultivated area shrinks and the urban population grows, so have food imports from South Africa. Even though maize is the primary agricultural product in the country, domestically-produced unrefined maize is actually more expensive than imported refined maize from South Africa [18]. As Reference [19] observes "growing numbers of Basotho can achieve some or all of their food security by buying food rather than growing it." So-called "rural" households rely on a variety of livelihood strategies and farming is just one, albeit declining, element in the mix. In addition, an estimated $60 \%$ of households are actually landless and for the majority of landholding households "instead of producing crops, harvesting rent has emerged as a predominant household land strategy for survival” [20].

Like the rest of Africa, Lesotho is experiencing a process of rapid urbanization with the urban proportion of the population growing from $2 \%$ in 1960 to $25 \%$ in 2008 . Reference [21] projects that the urban proportion of the 
population will increase to $54 \%$ by mid-century. The population of the capital city, Maseru, increased from 37,000 at independence in 1966 to 200,000 in 2006 to close to 300,000 in 2015. Several recent studies have documented the continued conversion of arable land into residential areas in response to unbridled urban expansion $[20,22,23]$. Despite the fact that the majority of Basotho still live in rural villages, urban-rural linkages are strong as most of the population lives in the lowlands in close proximity to urban centres. In addition, over 200,000 Basotho migrants live and work in urban areas across the border in South Africa and send remittances to support households in Lesotho. Food purchase is the single most important use of remittances [24]. What this means, in effect, is that Lesotho's population is actually far more urbanized than is suggested by the convenient enumeration of Basotho as having either a primary rural or urban residence rather than a combination of both.

As the urban population increases, and with it the incidence of urban food insecurity, the dominant rural productionist approach to food is beginning to frame the policy response. In particular, urban agriculture is increasingly being seen as a potential panacea for urban food insecurity. A World Food Programme study of urban food security in Lesotho concluded that "improving home gardens in urban areas through livelihood activities can contribute significantly to urban household food security" [25]. Several prominent non-governmental organizations have sought, with mixed results, to move forward on the supposed promise of urban agriculture and implement an urban gardens project [26]. And Lesotho's relatively successful rural keyhole gardens programme is seen as a natural option for space-constrained urban households [27].

Food production in Lesotho, however, faces a number of challenges. First, the environmental conditions in Lesotho are not conducive to agricultural productivity. The country has experienced severe droughts in recent decades as well as other extreme weather events [28]. As such, Lesotho has been considered very vulnerable to the impact of climate change. Reference [29] also suggests that hundreds of hectares of arable land may be lost to erosion every year in Lesotho. That said, the International Food Policy Research Institute has proposed (via their own projections) that climate change may actually stem the loss of arable land for maize production and productivity may actually increase in the coming decades [30].

The extent to which households in Lesotho can engage in agricultural production also rests upon the security of land tenure. Reference [31] suggest that land tenure provides assets which can buffer a household from the impact of hazards and provide a means of access to potentially arable land. However, the conflicting systems of land tenure in Maseru, which rest on both formal and traditional processes, can confound access to arable land [29]. Arable land has also been converted into residential zones [22]. Within Maseru, the space available for agricultural production appears to be dwindling as the city has continued to grow [20].

In this paper we take our critique of urban agriculture discourse a step further through a case study of the relationship between food insecurity and the practice of UA in the Lesotho capital, Maseru. Although the analysis is designed to shed light on a neglected aspect of the food security situation in Lesotho, the proposed methodology and findings have wider applicability. This paper reviews the food security challenges facing urbanizing Lesotho and assesses the extent to which urban food production in Maseru is tied to improved food security. The paper begins with a review of the production-oriented policy approach to food insecurity pursued both by the Lesotho government and by various international organizations and aid agencies. The paper then assesses the food security outcomes of urban agriculture practice using household survey data collected from 800 households in Maseru in 2008.

This paper investigates whether urban agriculture strategies in Maseru are associated with household food security gains. The paper has three main objectives:

- To compare the distribution of household food security scores with urban agriculture strategies among the sampled households;

- To assess the effectiveness of urban agriculture coping strategies in reducing the odds of household food insecurity among the sampled households;

- To examine the effectiveness of urban agriculture coping strategies in reducing the odds of household food insecurity across different income groups among the sampled households.

\section{Material and Methods}

The data in this investigation is from a 2008 survey of 800 low-income households in Maseru, Lesotho completed by the African Food Security Urban Network (AFSUN) in partnership with the National University of Lesotho. The surveyed constituencies were purposively selected given their identification as poor areas of the city by previous poverty mapping. The neighbourhoods selected for the survey included Lithoteng, Qoaling, and a combined housing neighbourhood area identified as SSTS (which included Tsoapo-le-Bolila, Ha Seoli, Ha Shelile, and Semphetenyane). Households were pre-selected within these neighbourhoods from fine scaled aerial photographs. This pre-selection phase of the survey ensured that the selected households were evenly spaced across the neighbourhoods. The household survey was then administered to the pre-selected households in these neighbourhoods. The AFSUN Household Food Security Baseline Survey was the instrument used in this survey. The AFSUN survey collects comprehensive data on household composition and demography, individual household members, poverty and income, livelihood strategies, food sourcing including urban agriculture, and food security indicators. The household survey was administered by trained enumerators. The respondents were household heads or adults capable of answering all survey questions on behalf of members of their respective households.

Table 1. Sampling distribution across sampled Maseru neighbourhoods [33]

\begin{tabular}{lcc}
\hline Neighbourhood & Sample Size & $\%$ \\
\hline Lithoteng & 296 & 37 \\
Qoaling & 344 & 43 \\
SSTS & 160 & 20 \\
Total & 800 & 100 \\
\hline
\end{tabular}


Table 2. Investigation variable descriptions for all frequency distributions

\begin{tabular}{|c|c|c|c|}
\hline Variables & Level & Values & \\
\hline HDDS & Binary & $>3$ food groups & $<=3$ food groups \\
\hline HFIAP & Binary & Food secure & Food insecure \\
\hline MAHFP & Binary & 12 months & $<12$ months \\
\hline Field crops & Binary & Not dependent & dependent \\
\hline Garden crops & Binary & Not dependent & dependent \\
\hline Tree crops & Binary & Not dependent & dependent \\
\hline Livestock & Binary & Not dependent & dependent \\
\hline Household income terciles & Ordinal & Middle income & High income \\
\hline Lived poverty index & Ordinal & Higher scores indicate less resource access & \\
\hline Urban agriculture utilization & Binary & Accessed any UA sources in the last year & Did not access any UA sources in the last year \\
\hline
\end{tabular}

With the exception of the ordinal income tercile and lived poverty index variables, the data analysis for this paper used binary level variables including the Household Dietary Diversity Score (HDDS); the Household Food Insecure Access Prevalence (HFIAP) scale; the Months of Adequate Household Food Provisioning (MAHFP) indicator; and household engagement in field crops, garden crops, tree crops and livestock rearing (Table 2).

The Household Dietary Diversity Score (HDDS) is a forced answer survey scale which measures the number of food groups consumed by an entire household in the 24 hours prior to the survey [34]. These food groups include grains, ground provisions, other vegetables, fruit, meat, eggs, fish/shellfish, beans, dairy, oils, sugar, and condiments. The final HDDS score is calculated as the total number of these different food groups which were consumed by any member of a household within the last 24 hours. In this investigation, this variable was collapsed into a binary variable which represented whether a household had consumed less than four or more food groups and less than four food groups in the previous 24 hours.

The Household Food Insecurity Access Prevalence scale (HFIAP) is a forced answer survey scale which includes 9 ordinal level questions asking the frequency of occurrence for different events associated with limited household food access [35]. Using a scoring algorithm, the answers to each question were then assessed and each household given a score between 1 and 4 (where 1 represents food security and 4 represents food insecurity). The HFIAP was then collapsed to a binary variable representing whether a household scored a 1 (demonstrating secure food access) or greater than 1 (demonstrating any level of insecure food access).

The Months of Adequate Household Food Provisioning (MAHFP) is also a forced answer survey scale which is designed to determine the number of months in the previous year in which a given household had sufficient food provisions [36]. This scale is a measure of the security of longer-term household food access. The final MAHFP score is represented as a number between 1 and 12 (representing months of the previous year during which a household maintained adequate food provisioning). This variable was collapsed to represent whether a household had 12 months of adequate food provisioning or less than 12 months of food provisioning.

In the survey, households were also asked about their livelihood strategies and urban agriculture practices were listed as possibilities. Household engagement in urban agriculture was disaggregated to demonstrate whether a household engaged in field crops, garden crops, tree crops, or the rearing of livestock as a livelihood strategy. These survey variables were also collapsed into binary variables (representing whether a household depended upon these practices as a livelihood strategy).

Finally, the analysis used household income and the lived poverty index. Household income refers to the total amount earned by an entire household across all income sources in the previous month. The household income variable has been collapsed into an ordinal variable representing three categories: low, middle, and high income. These categories were calculated by dividing the total household income into three equal proportions (terciles) based on the distributed frequency of all sampled household responses to this question. The Lived Poverty Index is an ordinal scale representing the frequency with which households have gone without key resources and services in the last year.

\subsection{Theory}

The theoretical framework for this investigation is derived from the Pressure and Release model from Disaster Risk Reduction literature. This model is used to define the qualities of a successful coping strategy [37]. According to this model, a coping strategy is meant to reduce the odds of a vulnerable population experiencing the impact of a hazard. Using this framework, the analysis defines food insecurity as the impact of a hazard on a vulnerable population. An effective coping strategy would therefore be associated with reduced odds of a household experiencing the impact of a hazard (in other words, experiencing food insecurity). This theoretical approach has been chosen for its amenability to statistical analysis.

\subsection{Calculation}

In order to compare the distribution of household food security scores across urban agriculture practices, this paper assesses the distributed frequency of all urban agriculture coping strategies (including field crops, garden crops, tree crops, and livestock rearing) by all three household food security scales included in this investigation. These distributed frequency cross-tabulations indicate the number of households who were both engaged in these urban agriculture activities and were also categorized as either food secure or food insecure according to the three food security scales. As such, the distribution provides insight into the differential frequency with which households engaged in these urban 
agriculture practices were either food secure or food insecure according to these scales.

To assess the effectiveness of urban agriculture coping strategies in reducing the odds of household food insecurity, the paper uses the cross-tabulations calculated for the first objective, and then presents odds ratio calculations. These odds ratios demonstrate whether engagement in urban agriculture is associated with decreased odds of household food insecurity. The statistical significance of these odds ratio calculations were determined by Pearson's chi-square tests of independence and Fisher's exact tests. These tests demonstrate the statistical probability that the crosstabulated frequency distribution reveals a statistically significant relationship between these variables as opposed to a random relationship between independent variables. The alpha set by this investigation for a statistically significant relationship in this investigation will be any p-value less than 0.05. In order for engagement in any form of urban agriculture practice to be associated with significantly different odds of food insecurity, the cross-tabulation of the urban agriculture practice with a given food security measure must have a p-value of less than 0.05 on both a Pearson's Chi-Square test and a Fisher's Exact Test.

Finally, to examine the effectiveness of urban agriculture coping strategies in reducing the odds of household food insecurity across income terciles, the same methodology was also implemented with one additional step. The odds ratios (and supporting Chi-square and Fisher's Exact tests) were calculated for each urban agriculture practice and food security score pairing within each of the three household income terciles (low, middle, and high income). This assessment determines the extent to which each urban agriculture practice in decreasing the odds of household food insecurity across income terciles. In other words, this determines whether the practices become more or less effective when comparing low to higher-income households in generally low-income areas of Maseru.

\subsection{Limitations}

These analyses are based on cross-sectional household survey data collected from poor areas of Maseru. As such, these analyses cannot make any causal claims or infer any kind of a temporal association between these variables. Given that the data was drawn from poor areas of the city, it is difficult to determine whether these relationships hold outside of the selected areas using this research alone. It is also possible that, if the alphas for any of the statistical tests used in this investigation or the thresholds used to create the binary variables were to change, the statistical significance of the analyses may change as well. While the analyses took into account the influence of household income terciles in determining the strength of association between the included variables, there may be other variables which may explain the relationships observed in this investigation but were not included in the household survey. Given these limitations, it will be important to validate the findings made in this paper before making any inferences about the generalizability, causal nature, or temporal characteristics of the associations between these variables.

\section{Results}

The sampled poor households in Maseru obtain their food from three major market sources and one non-market source but with varying degrees of frequency (Table 3). Small shops are the major source of purchased food, followed by supermarkets, although the latter are patronised less frequently. The growing informal food economy is regularly used as a source of food by around $50 \%$ of households. Just under a half of the households (47\%) obtain non-purchased food from urban agriculture, but only $21 \%$ do so on a regular basis (at least once a week). Only $2 \%$ of households obtain any income from the sale of urban agricultural products. Together, this data indicates that the majority of households do not engage in urban agriculture as a food source.

The most common urban household agricultural activities within Maseru include home gardens, particularly by low and middle income households; small-scale backyard commercial poultry and egg production and piggeries; milk production by members of the Lesotho Dairy Association; and subsistence livestock and crop farming. Around $30 \%$ of the surveyed households had gardens while $8 \%$ had fields and $9 \%$ had livestock.

A recurrent question in the literature on urban agriculture is whether the poorest and most food insecure households participate more than better-off households (Crush et al 2011). In the case of Maseru, the answer is very clear. Even in generally poor neighbourhoods, the poorest are least likely to engage in urban agriculture (Table 4). Only 33\% of households in the lowest income tercile had used urban agriculture as a food source in the previous year compared to $51 \%$ of households in the upper income tercile. There was a similar relationship with the Lived Poverty Index (LPI). As the LPI increases (indicating greater poverty), so the proportion of households involved in urban agriculture decreases.

Table 3. Sample household food sources in the last year by frequency of use

\begin{tabular}{|c|c|c|c|c|c|c|}
\hline \multirow[t]{2}{*}{ Food Source } & Total & $\begin{array}{l}\text { At least five } \\
\text { days a week }\end{array}$ & $\begin{array}{l}\text { At least once a } \\
\text { week }\end{array}$ & $\begin{array}{l}\text { At least once a } \\
\text { month }\end{array}$ & $\begin{array}{l}\text { At least once in } \\
\text { six months }\end{array}$ & $\begin{array}{c}\text { Less than once a } \\
\text { year }\end{array}$ \\
\hline & $\%$ & $\%$ & $\%$ & $\%$ & $\%$ & $\%$ \\
\hline Small shop/ restaurant/take away & 89 & 27 & 50 & 12 & 1 & $<1$ \\
\hline Supermarkets & 84 & 4 & 17 & 62 & 1 & 0 \\
\hline Informal market/ street food & 49 & 11 & 23 & 11 & 2 & 2 \\
\hline Urban agriculture & 47 & 8 & 13 & 9 & 13 & 3 \\
\hline
\end{tabular}

Note: More than one answer permitted

Source: Leduka et al. (2015). 
Table 4. Household urban agriculture utilization as a food source over the previous year

\begin{tabular}{|c|c|c|c|c|}
\hline Variable & Category & Yes (\%) & No (\%) & $\mathrm{n}$ \\
\hline \multirow[b]{2}{*}{ Household Income } & Low Income & 33 & 67 & 231 \\
\hline & Middle Income & 46 & 54 & 224 \\
\hline \multirow{4}{*}{ Lived Poverty Index } & $0-1$ & 47 & 53 & 280 \\
\hline & $1-2$ & 43 & 57 & 347 \\
\hline & $2-3$ & 35 & 65 & 124 \\
\hline & $3-4$ & 21 & 79 & 14 \\
\hline
\end{tabular}

Source: Leduka et al. (2015).

Table 5. Prevalence of urban agriculture practice among the sampled households

\begin{tabular}{|c|c|c|c|c|}
\hline Urban Agriculture Practice & & Dependent & Not Dependent & Total \\
\hline \multirow[t]{2}{*}{ Field crops } & $\mathrm{n}$ & 103 & 696 & 799 \\
\hline & $\%$ & $12.9 \%$ & $87.1 \%$ & $100 \%$ \\
\hline \multirow[t]{2}{*}{ Garden crops } & $\mathrm{n}$ & 485 & 313 & 798 \\
\hline & $\%$ & $60.8 \%$ & $39.2 \%$ & $100 \%$ \\
\hline \multirow[t]{2}{*}{ Tree crops } & $\mathrm{n}$ & 162 & 636 & 798 \\
\hline & $\%$ & $20.3 \%$ & $79.7 \%$ & $100 \%$ \\
\hline \multirow[t]{2}{*}{ Livestock } & $\mathrm{n}$ & 128 & 671 & 799 \\
\hline & $\%$ & $16 \%$ & $84 \%$ & $100 \%$ \\
\hline
\end{tabular}

Source: AFSUN (2008).

A frequency distribution of household engagement in the four types of urban agriculture being assessed in this investigation (field crops, garden crops, tree crops, and livestock) demonstrated some key insights about the prevalence of the different types of urban agriculture. Based on this distribution, it is evident that garden crops represent the most commonly practiced form of urban agriculture in the surveyed population (accounting for over $60 \%$ of households sampled in the survey). Across the sample distributions, engagement in some form of urban food production seems to be a relatively common practice with $16 \%$ of households tending livestock, $20.3 \%$ growing tree crops, $60.8 \%$ growing garden crops and $12.9 \%$ growing field crops (Table 5 ).

The cross-tabulation of household engagement in urban agriculture practices by household food security scores reveals some interesting comparisons. First, the majority of the households sampled in this survey of Maseru demonstrated some form of food insecurity. Among the sampled households, 63\% consumed fewer than four food groups in the last 24 hours. A surprising 95\% of households scored greater than one on the HFIAP (indicating some degree of food insecurity). Finally, around $84 \%$ of the sampled households had fewer than 12 months of adequate household food provisioning on the MAHFP.

Second, household engagement in tree crops was associated with a higher risk of a household being categorized as food insecure on the HFIAP. Aside from that exception, however, the rest of the urban agriculture practices were associated with a lower incidence of food insecurity across the three food security measures. That said, with the exception of the HDDS comparisons, the majority of the differences in the incidence of food insecurity were limited to under five percentage points difference (Table 6). Given the numerous slim margins observed in this table, it is difficult to draw any firm conclusions without taking into account the statistical significance of these differences.
Across the four urban agriculture practices, only household engagement in garden crops and livestock rearing demonstrated a statistically significant distribution with HDDS scores. However, these cross-tabulations demonstrated odds ratios values of .648 and .589 respectively, indicating that engagement in either of these activities was associated with significantly decreased odds of a limited diversity in the household diet. Household engagement in field crops and tree crops were associated with insignificant changes in the odds of limited household dietary diversity (Table 7).

The odds ratio calculations of urban agriculture engagement and household food access (as measured by the HFIAP) revealed that only engagement in field crops was significantly associated with lower odds of insecure household food access. The other urban agriculture practices did not indicate a statistically significant relationship and odds ratios whose $95 \%$ confidence intervals cross 1 (indicating that the relationship did not affect the household's odds of food insecurity). Together these results suggest that, apart from the field crops results, engagement in urban agriculture is not associated with greater odds of food access among the sampled households in Maseru (Table 8).

However, the odds ratio calculations for the various urban agriculture practices with the MAHFP scores does not confirm the findings for the HFIAP. Among these variables, only livestock rearing demonstrated a statistically significant relationship with MAHFP scores, where household engagement in livestock rearing was associated with significantly decreased odds that a household went without adequate monthly food provisions over the previous year. These calculations suggest that most forms of urban agriculture practice were not associated with statistically significant changes in the odds of a household experiencing long-term food access challenges. The only exception is livestock rearing which appeared to be associated with a significant difference in the odds of long-term food access (Table 9). 
Table 6. Distributed frequency of household urban agriculture coping strategies with food security scores

\begin{tabular}{|c|c|c|c|c|c|c|c|c|c|c|c|}
\hline \multirow{2}{*}{\multicolumn{3}{|c|}{$\begin{array}{l}\text { Urban Agriculture } \\
\text { Dependence }\end{array}$}} & \multicolumn{3}{|c|}{ HDDS } & \multicolumn{3}{|c|}{ HFIAP } & \multicolumn{3}{|c|}{ MAHFP } \\
\hline & & & $4+$ & $<=3$ & Total & Food Secure & Food Insecure & Total & 12 Months & $<12$ Months & Total \\
\hline \multirow{4}{*}{ Field crops } & \multirow{2}{*}{ No } & $\mathrm{n}$ & 242 & 425 & 667 & 28 & 661 & 689 & 111 & 571 & 682 \\
\hline & & $\%$ & $36.3 \%$ & $63.7 \%$ & $100 \%$ & $4.1 \%$ & $95.9 \%$ & $100 \%$ & $16.3 \%$ & $83.7 \%$ & $100 \%$ \\
\hline & \multirow{2}{*}{ Yes } & $\mathrm{n}$ & 42 & 56 & 98 & 9 & 94 & 103 & 18 & 81 & 99 \\
\hline & & $\%$ & $42.9 \%$ & $57.1 \%$ & $100 \%$ & $8.7 \%$ & $91.3 \%$ & $100 \%$ & $18.2 \%$ & $81.8 \%$ & $100 \%$ \\
\hline \multirow{4}{*}{ Garden crops } & \multirow{2}{*}{ No } & $\mathrm{n}$ & 93 & 207 & 300 & 12 & 299 & 311 & 49 & 259 & 308 \\
\hline & & $\%$ & $31.0 \%$ & $69.0 \%$ & $100 \%$ & $3.9 \%$ & $96.1 \%$ & $100 \%$ & $15.9 \%$ & $84.1 \%$ & $100 \%$ \\
\hline & \multirow{2}{*}{ Yes } & $\mathrm{n}$ & 190 & 274 & 464 & 25 & 455 & 480 & 80 & 392 & 472 \\
\hline & & $\%$ & $40.9 \%$ & $59.1 \%$ & $100 \%$ & $5.2 \%$ & $94.8 \%$ & $100 \%$ & $16.9 \%$ & $83.1 \%$ & $100 \%$ \\
\hline \multirow{4}{*}{ Tree crops } & \multirow{2}{*}{ No } & $\mathrm{n}$ & 218 & 392 & 610 & 30 & 602 & 632 & 103 & 523 & 626 \\
\hline & & $\%$ & $35.7 \%$ & $64.3 \%$ & $100 \%$ & $4.7 \%$ & $95.3 \%$ & $100 \%$ & $16.5 \%$ & $83.5 \%$ & $100 \%$ \\
\hline & \multirow{2}{*}{ Yes } & $\mathrm{n}$ & 66 & 88 & 154 & 7 & 152 & 159 & 26 & 128 & 154 \\
\hline & & $\%$ & $42.9 \%$ & $57.1 \%$ & $100 \%$ & $4.4 \%$ & $95.6 \%$ & $100 \%$ & $16.9 \%$ & $83.1 \%$ & $100 \%$ \\
\hline \multirow{4}{*}{ Livestock } & \multirow{2}{*}{ No } & $\mathrm{n}$ & 227 & 419 & 646 & 28 & 637 & 665 & 96 & 557 & 653 \\
\hline & & $\%$ & $35.1 \%$ & $64.9 \%$ & $100 \%$ & $4.2 \%$ & $95.8 \%$ & $100 \%$ & $14.7 \%$ & $85.3 \%$ & $100 \%$ \\
\hline & \multirow{2}{*}{ Yes } & $\mathrm{n}$ & 57 & 62 & 119 & 9 & 118 & 127 & 33 & 95 & 128 \\
\hline & & $\%$ & $47.9 \%$ & $52.1 \%$ & $100 \%$ & $7.1 \%$ & $92.9 \%$ & $100 \%$ & $25.8 \%$ & $74.2 \%$ & $100 \%$ \\
\hline
\end{tabular}

Source: AFSUN (2008).

Table 7. Odds ratio calculations of household urban agriculture engagement by Household Dietary Diversity score.

\begin{tabular}{|c|c|c|c|c|c|}
\hline & \multirow[b]{2}{*}{ Odds Ratio } & \multicolumn{2}{|c|}{ 95\% C.I. } & \multicolumn{2}{|c|}{ P-Values } \\
\hline & & Lower & Upper & Chi-Square & Fisher's Exact Test \\
\hline Field Crops & .759 & .494 & 1.167 & .208 & .219 \\
\hline Garden Crops** & .648 & 0.477 & 0.881 & .005 & .006 \\
\hline Tree Crops & .741 & 0.518 & 1.062 & .102 & .113 \\
\hline Livestock** & .589 & 0.397 & 0.874 & .008 & .010 \\
\hline
\end{tabular}

$* \mathrm{p}<.05$ on both Pearson's Chi-Square and Fisher's Exact Test

** $\mathrm{p}<.01$ on both Pearson's Chi-Square and Fisher's Exact Test.

Source: AFSUN (2008).

Table 8. Odds ratio calculations of household urban agriculture engagement by Household Insecure Access Prevalence score

\begin{tabular}{|c|c|c|c|c|c|}
\hline & \multirow[b]{2}{*}{ Odds Ratio } & \multicolumn{2}{|c|}{ 95\% C.I. } & \multicolumn{2}{|c|}{ P-Values } \\
\hline & & Lower & Upper & Chi-Square & Fisher's Exact Test \\
\hline Field Crops* & .442 & .203 & .967 & .036 & .045 \\
\hline Tree Crops & 1.082 & 0.466 & 2.511 & .854 & 1.000 \\
\hline Livestock & .576 & 0.265 & 1.253 & .159 & .168 \\
\hline
\end{tabular}

$* \mathrm{p}<.05$ on both Pearson's Chi-Square and Fisher's Exact Test

** $\mathrm{p}<.01$ on both Pearson's Chi-Square and Fisher's Exact Test.

Source: AFSUN (2008).

Table 9. Odds ratio calculations of household urban agriculture engagement by MAHFP score

\begin{tabular}{|c|c|c|c|c|c|}
\hline & \multirow[b]{2}{*}{ Odds Ratio } & \multicolumn{2}{|c|}{ 95\% C.I. } & \multicolumn{2}{|c|}{ P-Values } \\
\hline & & Lower & Upper & Chi-Square & Fisher's Exact Test \\
\hline Field Crops & .875 & .505 & 1.516 & .633 & .664 \\
\hline Garden Crops & .927 & 0.628 & 1.367 & .702 & .768 \\
\hline Tree Crops & .970 & 0.605 & 1.554 & .898 & .904 \\
\hline Livestock** & .496 & 0.316 & 0.779 & .002 & .004 \\
\hline
\end{tabular}

$* \mathrm{p}<.05$ on both Pearson's Chi-Square and Fisher's Exact Test

$* * \mathrm{p}<.01$ on both Pearson's Chi-Square and Fisher's Exact Test.

Source: AFSUN (2008).

The challenge in making these comparisons across urban agriculture practices is determining the role which income plays in these reduced odds of food insecurity. For example, do households engaged in urban agriculture actually have a significantly higher income (which may better explain the changes in the odds of household food security)? When household engagement in field crops, garden crops, tree crops and livestock are cross-tabulated with household income terciles, an interesting trend emerges. Engagement in each of these urban agriculture practices increases across household income terciles. The cross-tabulations of household income terciles with field crops $x^{2}(2, n=699)=7.765$, $p=0.021)$ and livestock $x^{2}(2, n=699)=23.247$, $p<0.001)$ are actually statistically significant at an alpha 
of 0.05 using a Pearson's chi-square test. That said, this distribution was not statistically significant for the cross-tabulations of household income terciles and garden crops $\left.x^{2}(2, n=698)=4.284, p=0.117\right)$ and tree crops $\left.x^{2}(2, n=698)=0.894, p=0.643\right)$. Given these distributions, it is necessary to rule out the influence of household income in determining the association between urban agriculture and household food security.

Table 10. Frequency distribution of urban agriculture practices by household income terciles.

\begin{tabular}{|c|c|c|c|c|c|}
\hline \multicolumn{3}{|c|}{ Urban Agriculture Dependence } & \multicolumn{3}{|c|}{ Terciles of Household Income } \\
\hline & & & \multirow{2}{*}{$\frac{\text { Low income }}{215}$} & \multirow{2}{*}{$\frac{\text { Middle income }}{195}$} & \multirow{2}{*}{$\frac{\text { High income }}{211}$} \\
\hline Field crops & Not Dependent & $\mathrm{n}$ & & & \\
\hline & Dependent & $\mathrm{n}$ & 15 & 28 & 35 \\
\hline & & $\%$ & $6.5 \%$ & $12.6 \%$ & $14.2 \%$ \\
\hline & Total & $\mathrm{n}$ & 230 & 223 & 246 \\
\hline & & $\%$ & $100.0 \%$ & $100.0 \%$ & $100.0 \%$ \\
\hline \multirow[t]{5}{*}{ Garden crops } & Not Dependent & $\mathrm{n}$ & 99 & 92 & 84 \\
\hline & & $\%$ & $43.0 \%$ & $41.3 \%$ & $34.3 \%$ \\
\hline & Dependent & $\mathrm{n}$ & 131 & 131 & 161 \\
\hline & & $\%$ & $57.0 \%$ & $58.7 \%$ & $65.7 \%$ \\
\hline & Total & $\mathrm{n}$ & 230 & 223 & 245 \\
\hline \multirow[t]{6}{*}{ Tree crops } & Not Dependent & $\mathrm{n}$ & 190 & 176 & 197 \\
\hline & & $\%$ & $82.6 \%$ & $79.3 \%$ & $80.1 \%$ \\
\hline & Dependent & $\mathrm{n}$ & 40 & 46 & 49 \\
\hline & & $\%$ & $17.4 \%$ & $20.7 \%$ & $19.9 \%$ \\
\hline & Total & $\mathrm{n}$ & 230 & 222 & 246 \\
\hline & & $\%$ & $100.0 \%$ & $100.0 \%$ & $100.0 \%$ \\
\hline \multirow[t]{6}{*}{ Livestock } & Not Dependent & $\mathrm{n}$ & 212 & 192 & 188 \\
\hline & & $\%$ & $92.2 \%$ & $86.1 \%$ & $76.4 \%$ \\
\hline & Dependent & $\mathrm{n}$ & 18 & 31 & 58 \\
\hline & & $\%$ & $7.8 \%$ & $13.9 \%$ & $23.6 \%$ \\
\hline & Total & $\mathrm{n}$ & 230 & 223 & 246 \\
\hline & & $\%$ & $100.0 \%$ & $100.0 \%$ & $100.0 \%$ \\
\hline
\end{tabular}

Source: AFSUN (2008).

Table 11. Odds ratio calculations of household urban agriculture engagement by Household Dietary Diversity score according to household income tercile

\begin{tabular}{|c|c|c|c|c|c|}
\hline & \multirow[b]{2}{*}{ Odds Ratio } & \multicolumn{2}{|c|}{ 95\% C.I. } & \multicolumn{2}{|c|}{ P-Values } \\
\hline & & Lower & Upper & Chi-Square & Fisher's Exact Test \\
\hline \multicolumn{6}{|l|}{ Low Income } \\
\hline Field Crops & 1.121 & .300 & 4.183 & .865 & 1.000 \\
\hline Garden Crops & .515 & .265 & 1.001 & .048 & .054 \\
\hline Tree Crops & 1.121 & .477 & 2.635 & .793 & 1.000 \\
\hline \multicolumn{6}{|l|}{ Middle Income } \\
\hline Field Crops & .774 & .327 & 1.830 & .558 & .649 \\
\hline Garden Crops & .775 & .423 & 1.419 & .408 & .448 \\
\hline Tree Crops & .563 & .281 & 1.128 & .103 & .134 \\
\hline Livestock & .943 & .390 & 2.283 & .897 & 1.000 \\
\hline \multicolumn{6}{|l|}{ High Income } \\
\hline Field Crops & .932 & .439 & 1.978 & .854 & 1.000 \\
\hline Garden Crops & .942 & .545 & 1.627 & .830 & .889 \\
\hline Tree Crops & .697 & .357 & 1.360 & .288 & .323 \\
\hline Livestock & .782 & .419 & 1.459 & .439 & .531 \\
\hline
\end{tabular}

$* \mathrm{p}<.05$ on both Pearson's Chi-Square and Fisher's Exact Test

** $\mathrm{p}<.01$ on both Pearson's Chi-Square and Fisher's Exact Test.

Source: AFSUN (2008). 
Table 12. Odds ratio calculations of household urban agriculture engagement by HFIAP and household income tercile

\begin{tabular}{|c|c|c|c|c|c|}
\hline & \multirow[b]{2}{*}{ Odds Ratio } & \multicolumn{2}{|c|}{ 95\% C.I. } & \multicolumn{2}{|c|}{ P-Values } \\
\hline & & Lower & Upper & Chi-Square & Fisher's Exact Test \\
\hline \multicolumn{6}{|l|}{ Low Income } \\
\hline Field Crops & NA & NA & NA & .790 & 1.000 \\
\hline Garden Crops & NA & NA & NA & .248 & .430 \\
\hline Tree Crops & NA & NA & NA & .649 & 1.000 \\
\hline Livestock & NA & NA & NA & .776 & 1.000 \\
\hline \multicolumn{6}{|l|}{ Middle Income } \\
\hline Field Crops* & .133 & .025 & .695 & .006 & .029 \\
\hline Garden Crops & .697 & .125 & 3.887 & .679 & 1.000 \\
\hline Tree Crops & 1.310 & .149 & 11.498 & .807 & 1.000 \\
\hline Livestock & .820 & .093 & 7.262 & .858 & 1.000 \\
\hline \multicolumn{6}{|l|}{ High Income } \\
\hline Field Crops & .880 & .243 & 3.191 & .845 & .740 \\
\hline Garden Crops & 1.121 & .424 & 2.964 & .817 & .806 \\
\hline Tree Crops & .907 & .287 & 2.866 & .867 & .771 \\
\hline Livestock & .858 & 295 & 2.492 & .778 & .781 \\
\hline
\end{tabular}

$* \mathrm{p}<.05$ on both Pearson's Chi-Square and Fisher's Exact Test

** $\mathrm{p}<.01$ on both Pearson's Chi-Square and Fisher's Exact Test.

Source: AFSUN (2008).

Table 13. Odds ratio calculations of household urban agriculture engagement by MAHFP and household income tercile

\begin{tabular}{|c|c|c|c|c|c|}
\hline & \multirow[b]{2}{*}{ Odds Ratio } & \multicolumn{2}{|c|}{ 95\% C.I. } & \multicolumn{2}{|c|}{ P-Values } \\
\hline & & Lower & Upper & Chi-Square & Fisher's Exact Test \\
\hline \multicolumn{6}{|l|}{ Low Income } \\
\hline Field Crops & NA & NA & NA & .246 & .612 \\
\hline Garden Crops & 1.066 & .424 & 2.685 & .891 & 1.000 \\
\hline Tree Crops & .795 & .250 & 2.526 & .697 & .754 \\
\hline Livestock & .762 & .162 & 3.581 & .730 & .666 \\
\hline \multicolumn{6}{|l|}{ Middle Income } \\
\hline Field Crops & .506 & .186 & 1.380 & .177 & .228 \\
\hline Garden Crops & .791 & .357 & 1.757 & .565 & .691 \\
\hline Tree Crops & 1.327 & .477 & 3.690 & .587 & .807 \\
\hline Livestock** & .207 & .086 & .496 & $<.001$ & .001 \\
\hline \multicolumn{6}{|l|}{ High Income } \\
\hline Field Crops & .785 & .353 & 1.749 & .553 & .531 \\
\hline Garden Crops & 1.078 & .582 & 1.996 & .811 & .875 \\
\hline Tree Crops & .789 & .383 & 1.624 & .519 & .569 \\
\hline Livestock & 1.032 & .518 & 2.057 & .928 & 1.000 \\
\hline
\end{tabular}

$* \mathrm{p}<.05$ on both Pearson's Chi-Square and Fisher's Exact Test

$* * \mathrm{p}<.01$ on both Pearson's Chi-Square and Fisher's Exact Test.

Source: AFSUN (2008).

The odds ratio calculations for the relationship between the urban agriculture practices and household food diversity (HDDS) scores by income tercile demonstrates found no statistically significant relationship according to both Chi-Square and Fisher's exact tests. The only exception to this observation is engagement in garden crops amongst the lowest income households. This relationship indicated a significant Chi-Square value and an insignificant Fisher's exact test. Even so, the 95\% confidence interval for the odds ratio estimate included 1 (.265-1.001), indicating a high probability that, among the sampled households, engagement in garden crops did not have any impact on the odds of a household having low dietary diversity (Table 11).
The comparatively low incidence of urban agriculturalists among food secure households (as measured by the HFIAP) provided challenges in calculating the odds ratios amongst the lowest income households (where there were too few households to calculate odds ratios for any of the urban agriculture practices included in this investigation). Across the remaining income terciles, only middle income households demonstrated a statistically significant relationship between engagement in field crops and HFIAP scores (according to Chi-square and Fisher's exact tests). This finding suggests that household engagement in field crops significantly decreases the odds of some households having reduced food access among the sampled middle-income households in Maseru (Table 12). 
The relationship between the four urban agriculture practices and MAHFP scores among households disaggregated by income indicates no statistically significant relationships, with the exception of livestock rearing. Middle income households engaged in rearing livestock had significantly lower odds of going without adequate household food provisions in the previous year when compared to households not engaged in the practice. Overall, however, these odds ratio calculations continue to indicate a weak relationship between urban agriculture practice and food security among the sampled households (Table 13). That said, it is also important to note that there were too few low-income households engaged in field crops to calculate odds ratios for this portion of the household sample.

\section{Discussion}

The majority of statistical tests in this investigation did not demonstrate a statistically significant relationship between urban agriculture and household food security. In a few cases, urban agriculture practice significantly decreased the odds that a household would be categorized as food insecure on one of the food security measures included in this investigation. For example, there was a positive relationship between household engagement in field cropping and household food access (as measured by the HFIAP). Among households in the middle income tercile, household engagement in field crops also significantly reduced the odds that a household would have limited food access.

For those urban agriculture practices that had a statistically significant relationship with household food security, income did appear to explain these relationships among households in Maseru. The statistical significance or odds ratios observed in statistical tests of this relationship seemed to significantly change across household income tercile categories. For example, when income categories were taken into account, the relationship between garden crop engagement or livestock rearing and household dietary diversity was no longer statistically significant among the sampled households. In addition, the statistically significant relationship between engagement in garden crops and HFIAP scores only remained significant among the middle-income households included in the sample. Similarly, the statistically significant relationship between livestock rearing and MAHFP scores also only remained significant among middle-income households in the sample. In fact, when income categories were accounted for, only middle-income households demonstrated any statistically significant decreases in the odds of food insecurity based on urban agriculture engagement.

These statistical tests may have been confounded by the reduced sample size for these tests. This was certainly the case for the statistical tests of the relationship between agricultural practice and HFIAP scores among the lowest income households. In these tests, there were too few food secure households also engaged in urban agriculture. While it was impossible to calculate odds ratios, the absence of food secure, low income households engaged in some forms of urban agriculture may itself suggest that urban agriculture is not an effective practice for the poorest households. The distribution of household urban agriculture practices across household income terciles also indicated that household engagement in these practices was the least prevalent among low income households. Together, these observations indicate that, perhaps counter-intuitively, urban agriculture does not appear to be widely practiced, or benefited from, by low-income households in Maseru.

Given the extensive hagiographic literature on urban agriculture, this analysis questions the taken-for-granted argument about the quality and strength of the relationship between household engagement in urban agriculture and household food security. At best, the analysis demonstrates a weak and inconsistent relationship between household engagement in urban agriculture and household food security among the sampled households in Maseru. The findings from this investigation also demonstrate that household income did change the strength or quality of the relationship between urban agriculture practice and food security, as was previously suggested by Reference [8].

The analysis questions whether a production-centred understanding and policy response to food insecurity among urban households in Maseru is sufficient. Given the lack of a consistent relationship between urban agriculture and household food security in this city, and the broader characteristics of agricultural activity and food trade in Lesotho, urban household food security may require an alternative policy approach. As Reference [38] notes "promoting job creation may be the most effective way of enhancing Lesotho's food security in the medium to long term." In this respect, the Lesotho government may achieve greater food security gains by working to ensure that Basotho have greater formal and informal employment opportunities both in the country and in South Africa. In terms of the broader applicability of this analysis to the literature on urban agriculture and food insecurity, if the findings from this household survey in Maseru are replicated in other African cities, then serious questions need to be asked about the general pursuit and advocacy of production-centred policy approaches to rising urban food insecurity.

\section{Acknowledgements}

The authors would like to acknowledge the support of the Social Sciences and Humanities Research Council of Canada (SSHRC) and the International Development Research Centre (IDRC). The assistance of Dr Clement Leduka with the research component is also acknowledged.

\section{Statement of Competing Interests}

The authors of this manuscript are neither involved in nor affiliated with any organisations or entities that have either a financial or non-financial interest in the research presented in this manuscript.

\section{References}

[1] Lee-Smith, D, "Which Way for UPA in Africa," Cities, 17. 69-84. 2013. 
[2] Lee-Smith, D, The Dynamics of Urban and Peri-Urban Agriculture. In A. Akinyoade, W. Klaver, S. Soeters and D. Foeken, (eds.), Digging Deeper: Inside Africa's Agricultural, Food and Nutrition Dynamics, Brill, Leiden, 2014, 197-216.

[3] Padgham, J., Jabbour, J., and Dietrich, K, "Managing change and building resilience: A multi-stressor analysis of urban and peri-urban agriculture in Africa and Asia," Urban Climate, 12. 183-204. 2015

[4] Redwood, M. (Ed.), Agriculture in Urban Planning: Generating Livelihoods and Food Security, Routledge, London, 2009.

[5] Warren, E., Hawkesworth, S., and Knai, C, "Investigating the association between urban agriculture and food security, dietary diversity, and nutritional status: A systematic literature review," Food Policy, 53. 54-66. 2015.

[6] Badami, M., and Ramankutty, M, "Urban agriculture and food security: A critique based on an assessment of urban land constraints," Global Food Security, 4. 8-15. 2015

[7] Crush, J., Hovorka, A., \& Tevera, D, "Food security in Southern African cities: The place of urban agriculture," Progress in Development Studies, 11. 285-305. 2011.

[8] Frayne, B., McCordic, C., and Shilomboleni., H, “Assessing contributions of urban agriculture to household food security in Southern African cities," Urban Forum, 25(2). 177-189. 2014.

[9] BOS, Lesotho Urban Agricultural Report 2013/2014 (Statistical Report No. 11), Bureau of Statistics, Maseru, 2013.

[10] BOS, Lesotho Urban Agricultural Report 2013/2014 (Statistical Report No. 7), Bureau of Statistics, Maseru, 2015.

[11] GOL, Lesotho food security policy and strategic guidelines, Ministry of Agriculture and Food Security, Maseru, 2005.

[12] GOL, National action plan for food security (NAPFS), Ministry of Agriculture and Food Security, Maseru, 2006.

[13] GOL, National strategic development plan (NSDP) 2012/132016/17: Growth and development strategic framework (Maseru), Ministry of Agriculture and Food Security, Maseru, 2012.

[14] Gwimbi, P., Likoetla, P., Thabane, K., and Matebesi, P, A Comprehensive Scoping and Assessment Study of Climate Smart Agriculture (CSA) Policies in Lesotho, Food, Agriculture and Natural Resources Policy Analysis Network, Pretoria, 2014.

[15] Turner, S, Promoting food security in Lesotho: Issues and options, Report for Priority Support Programme, Maseru, 2009, 1.

[16] Crush, J. and Frayne, B, Feeding African Cities: The Growing Challenge of Urban Food Insecurity. In S. Parnell and E. Pieterse, eds., Africa’s Urban Revolution. Zed Books, London, 2014, 110-132.

[17] Turner, S, Promoting food security in Lesotho: Issues and options, Report for Priority Support Programme, Maseru, 2009.

[18] Mukeere, B., and Dradri, S, Food Aid, Food Production and Food Markets in Lesotho: An Analytical Review, FAO, Rome, 2006.

[19] Turner, S, Promoting food security in Lesotho: Issues and options, Report for Priority Support Programme, Maseru, 2009, vii.

[20] Thebe, V., and Rakotje, M, "Land Strategies and Livelihood Dynamics in Peri-urban Communities: Challenges to Land and Agricultural Policy in Lesotho,” African Studies, 72. 399-415. 2013, 400 .

[21] UNHABITAT, The State of African Cities 2014, UNHABITAT, Nairobi, 2014, 266.
[22] Daemane, M, \& Mot'soene, K, “Transactional Loss of Land Threatening Sustainable Development of Livelihoods in Urban Maseru," Journal of Sustainable Development in Africa, 14 132-144. 2012.

[23] Mot'soene, K, Urbanization and Poverty in Maseru: A Comparative Study of Sekamaneng, Motimposo and Thibella (Doctoral dissertation), University of the Witwatersrand, Johannesburg, 2014.

[24] Crush, J., Dodson, B., Gay, J., Green, T., and Leduka, C, Migration, remittances and 'development' in Lesotho (SAMP Migration Policy Series No. 52), SAMP, Cape Town, 2010.

[25] WFP, Vulnerability and Food Insecurity in Urban Areas of Lesotho, World Food Programme, Rome, 2008, 26.

[26] Noble, C, Small Plots, Big Hopes: Factors Associated with Participation in an Urban Garden Project in Lesotho (MA Thesis) University of South Florida, Tampa, 2010.

[27] CRS. Innovations in agriculture: Growing gardens in urban and peri-urban areas of Lesotho. Catholic Relief Services, Maseru, n.d.

[28] Obioha, E.E, “Climate variability and food production nexus in Lesotho, 2001 - 2007," Journal of Human Ecology, 32(3). 149-160. 2010.

[29] Marais, L, "Urbanisation, urban dilemmas and urban challenges in Lesotho,” Acta Academica, 33(2). 88-109. 2001.

[30] Gwimbi, P., Thomas, T.S., Hachigonta, S., and Sibanda, L.M, Lesotho. In S. Hachigonta, G.C. Nelson, T.S. Thomas, and L.M. Sibanda (Eds.), Southern African agriculture and climate change: A comprehensive analysis, IFPRI, Washington, 2013, 71-109.

[31] Turner, S., and Adams, M, A Note on Food Security and Land Tenure Security in Lesotho, SARPN, Pretoria, 2004.

[32] Gwimbi, P., Thomas, T.S., Hachigonta, S., and Sibanda, L.M, Lesotho. In S. Hachigonta, G.C. Nelson, T.S. Thomas, and L.M. Sibanda (Eds.), Southern African agriculture and climate change: A comprehensive analysis, IFPRI, Washington, 2013, 71-109.

[33] Leduka, R., Crush, J., Frayne, B., McCordic, C., Matobo, T., Makoa, T. E., ... Letsie, M, The state of poverty and food insecurity in Maseru, Lesotho, AFSUN, Cape Town, 2015.

[34] Swindle, A. and Bilinsky, P, Household dietary diversity score (HDDS) for measurement of household food access: Indicator guide, USAID, Washington, 2005.

[35] Coates, J., Swindle, A. and Bilinsky, P, Household food insecurity access scale (HFIAS) for measurement of food access: Indicator guide (Version 3), USAID, Washington, 2007.

[36] Bilinsky, P. and Swindle, A, Months of adequate household food provisioning (MAHFP) for measurement of household food access: Indicator guide (Version 4). USAID, Washington, 2010.

[37] Birkmann, J, Measuring vulnerability to promote disaster-resilient societies: Conceptual frameworks and definitions. In J. Birkmann (ed.), Measuring vulnerability to natural hazards: Towards disaster resilient societies (Vol. 01), United Nations University Press, New York, 2006, 9-54.

[38] Turner, S, Promoting food security in Lesotho: Issues and options, Report for Priority Support Programme, Maseru, 2009, 10.

[39] AFSUN, Regional Household File (Version 1). [SPSS]. African Food Security Urban Network, Cape Town, 2008. 